\title{
Polling on police use of body cameras: The effect of response option order on distribution and concurrent validity
}

\author{
Dana Garbarski ${ }^{1}$, Keyla Navarrete ${ }^{1}$, David Doherty ${ }^{2}$ \\ ${ }^{1}$ Sociology, Loyola University Chicago, ${ }^{2}$ Political Science, Loyola University Chicago \\ Keywords: response option order effects, policing \\ https://doi.org/10.29115/SP-2021-0009
}

Survey Practice

Vol. 14, Issue 1, 2021

Debates on key features of policing are far from settled and are highly politicized. However, a majority of the public favors the use of body cameras when asked whether they favor or oppose their use. Knowing that "favoring" overall might encompass several perspectives, we sought to document how frequently the public thought police should use body cameras: all the time with no exceptions, all the time with minimal exceptions, some of the time, or never. We were then confronted with a perennial survey design issue-how to order these response options in our web survey? We randomly assigned respondents to receive one of two response option orderings: from "never" to "all the time with no exceptions" and the reverse. Because we asked respondents about their support for or attitudes about items related to policing, we had the opportunity to examine the concurrent validity of each of the two versions of the item by examining their correlation with the related items. Overall, the results suggest when polling about police use of body cameras in terms of relative frequencies, the response options should be ordered starting with "never" or the lowest frequency.

The United States is engaged in a national conversation on policing. Debates on key features of policing are far from settled and are highly politicized. However, one point seems to have some convergence among the public and police: a majority of each favor the use of body cameras- $66 \%$ of officers and 93\% of the public — when asked whether they favor or oppose their use (Parker 2017).

Knowing that "favoring" overall might encompass several perspectives, we sought to document how frequently the public thought police should use body cameras: all the time with no exceptions, all the time with minimal exceptions, some of the time, or never. We were then confronted with a perennial survey design issue-how to order these response options in our web survey?

Beginning with the least desirable response option increases the likelihood that respondents consider a range of response options (Bradburn, Sudman, and Wansink 2004; Sudman and Bradburn 1982). Given the overwhelming public support favoring police use of body cameras, this suggests starting with "never." However, we wanted to empirically examine whether doing so

\footnotetext{
a Dana Garbarski, Department of Sociology, Loyola University Chicago

1032 W. Sheridan Rd., Chicago, IL 60660

dgarbarski@luc.edu

1(773)508-3445
} 
Table 1. Distribution of Frequency of Police Use of Body Cameras by Response Option Ordering among Cook County Residents, Dynata (February-March 2021).

\begin{tabular}{lll} 
& "All the Time" to "Never" & "Never" to "All the Time" \\
\hline All the time with no exception & $63.8 \%$ & $56.5 \%$ \\
All the time with minimal exception & $25.6 \%$ & $25.8 \%$ \\
Some of the time & $7.8 \%$ & $15.1 \%$ \\
Never & $2.9 \%$ & $2.6 \%$ \\
$\mathrm{~N}$ & $618 \%$ & $577 \%$ \\
\hline
\end{tabular}

Notes. Columns sum to $100 \%$. Chi-square $(\mathrm{df}=3)=16.84$, $\mathrm{p}<0.001$, Cramer's V=0.119

Question text: Police use of body-worn cameras varies across municipalities. When do you think police should use body worn cameras?

- All the time with no exceptions

- All the time with minimal exceptions (for example, when requested by the victim of a crime)

- Some of the time (for example, when investigating criminal activity but not when interviewing witnesses)

- Never

This question was presented vertically in all modes.

improved data quality. Thus, we randomly assigned respondents to receive one of two response option orderings: from "never" to "all the time with no exceptions" and the reverse. Importantly, because we asked respondents about their support for or attitudes about items related to policing, we had the opportunity to examine the concurrent validity of each of the two versions of the item by examining their correlation with the related items.

We fielded our survey from February through March 2021 using an online panel of respondents from Dynata, achieving a 65\% participation rate $(\mathrm{N}=1,195)$. The population was adult residents of Cook County, IL, which includes Chicago and its immediate suburbs. The survey was administered in English, and individual questions were administered page-by-page.

Table 1 shows that response distributions varied by scale direction. Respondents were more likely to choose "all the time with no exceptions" when it was the first option listed compared to the last, and respondents were more likely to choose "some of the time" when "never" was presented first compared to last. This is consistent with the literature on response option order effects: options near the beginning of the scale, particularly the first response option respondents perceive as acceptable, are more likely to be chosen (Garbarski, Schaeffer, and Dykema 2019; Krosnick 1991; Yan and Keusch 2015; Yan, Keusch, and He 2018). We also confirmed that the difference in the distribution by response option order is largely similar across device type (desktop/laptop vs. smartphone/tablet, not shown) (Krebs and Höhne 2021; Leon, Aizpurua, and van der Valk, Forthcoming).

Table 2 shows the correlations between each version of the body camera question and criteria of interest. When the response options for body camera are ordered from "never" to "all the time with no exceptions," the correlation is larger between body camera use and the following items: support for 
Table 2. Polychoric Correlations of Frequency of Police Use of Body Cameras with Criteria among Cook County Residents, Dynata (February-March 2021).

\begin{tabular}{|c|c|c|c|}
\hline & Overall & "All the Time" to "Never" & "Never" to "All the Time" \\
\hline $\begin{array}{l}\text { Support for police licensing } \\
\text { (higher score indicates more support) }\end{array}$ & 0.38 & 0.40 & 0.36 \\
\hline$N$ & 1,195 & 618 & 577 \\
\hline $\begin{array}{l}\text { Support for prosecuting police for excessive force } \\
\text { (higher score indicates more support) }\end{array}$ & 0.39 & 0.30 & $0.47^{* * *}$ \\
\hline$N$ & 1,195 & 618 & 577 \\
\hline $\begin{array}{l}\text { Police use of force in city } \\
\text { (higher score indicates worse rating) }\end{array}$ & -0.24 & -0.19 & -0.28 \\
\hline$N$ & 1,195 & 618 & 577 \\
\hline $\begin{array}{l}\text { Police use of force in suburbs } \\
\text { (higher score indicates worse rating) }\end{array}$ & -0.16 & -0.09 & $-0.22^{*}$ \\
\hline$N$ & 1,194 & 618 & 576 \\
\hline $\begin{array}{l}\text { Police treat people fairly in city } \\
\text { (higher score indicates worse rating) }\end{array}$ & -0.28 & -0.24 & -0.32 \\
\hline$N$ & 1,195 & 618 & 577 \\
\hline $\begin{array}{l}\text { Police treat people fairly in suburbs } \\
\text { (higher score indicates worse rating) }\end{array}$ & -0.21 & -0.15 & $-0.26^{*}$ \\
\hline $\mathrm{N}$ & 1,194 & 617 & 577 \\
\hline
\end{tabular}

Notes. Tests of whether the correlations between police body camera use and each criterion are significantly different across the response option order of police body camera use were conducted on quantpsy.org using Fisher's r-to-z transformation.

Question texts:

Q30: Occupational licensing exists to verify the training, testing, and education of people in certain professions, such as electricians and dental hygienists. If occupational licensing were required for police officers, an officer's license could be suspended if they are arrested or indicted for a felony. The Illinois Law Enforcement Training Standards Board would hear the officer's case and decide whether their license should remain suspended.

How much do you support or oppose a proposal that requires police officers to be licensed?

Strongly support, somewhat support, neither support nor oppose, somewhat oppose, strongly oppose

Q31: How much do you support or oppose a proposal to prosecute police officers who use excessive force?

Strongly support, somewhat support, neither support nor oppose, somewhat oppose, strongly oppose

Q34: How would you rate the job police officers in the city of Chicago are doing when it comes to using the right amount of force for each situation? Very good, good, poor, very poor

Q35: How would you rate the job police officers in the Chicago suburbs are doing when it comes to using the right amount of force for each situation? Very good, good, poor, very poor

Q36: How would you rate the job police officers in the city of Chicago are doing when it comes to treating people fairly regardless of race or ethnicity? Very good, good, poor, very poor

Q37: How would you rate the job police officers in the Chicago suburbs are doing when it comes to treating people fairly regardless of race or ethnicity? Very good, good, poor, very poor

Respondents were randomly assigned to receive very good-very poor or very poor-very good for Q34-37. The distribution of these items does not vary by response option order, so we combine across response option order for analysis.

prosecuting police for use of excessive force and how well the police in the suburbs are doing using the right amount of force for each situation and treating people fairly, regardless of race or ethnicity. 
Overall, the results suggest when polling about police use of body cameras in terms of relative frequencies, the response options should be ordered starting with "never" or the lowest frequency.

Submitted: June 02, 2021 EDT, Accepted: July 14, 2021 EDT 


\section{REFERENCES}

Bradburn, Norman M., Seymour Sudman, and Brian Wansink. 2004. Asking Questions: The Definitive Guide to Questionnaire Design for Market Research, Political Polls, and Social and Health Questionnaires. San Francisco: Jossey-Bass.

Garbarski, Dana, Nora Cate Schaeffer, and Jennifer Dykema. 2019. "The Effects of Features of Survey Measurement on Self-Rated Health: Response Option Order and Scale Orientation.” Applied Research in Quality of Life 14 (2): 545-60. https://doi.org/10.1007/s11482-018-9628-x.

Krebs, Dagmar, and Jan Karem Höhne. 2021. "Exploring Scale Direction Effects and Response Behavior Across Pc and Smartphone Surveys.” Journal of Survey Statistics and Methodology 9 (3): 477-95. https://doi.org/10.1093/jssam/smz058.

Krosnick, Jon A. 1991. "Response Strategies for Coping with the Cognitive Demands of Attitude Measures in Surveys.” Applied Cognitive Psychology 5 (3): 213-36. https://doi.org/10.1002/ acp. 2350050305 .

Leon, Carmen M., Eva Aizpurua, and Sophie van der Valk. Forthcoming. "Agree or Disagree: Does It Matter Which Comes First? An Examination of Scale Direction Effects in a Multi-Device Online Survey.” Field Methods. https://doi.org/10.1177/1525822×211012259.

Parker, Kim. 2017. "Behind the Badge: Amid Protests and Calls for Reform, How Police View Their Jobs, Key Issues and Recent Fatal Encounters Between Blacks and Police.” Pew Research Center.

Sudman, Seymour, and Norman M. Bradburn. 1982. “Asking Questions.” New Jersey: Jossey-Bass.

Yan, Ting, and Florian Keusch. 2015. "The Effects of the Direction of Rating Scales on Survey Responses in a Telephone Survey.” Public Opinion Quarterly 79 (1): 145-65. https://doi.org/ 10.1093/poq/nfu062.

Yan, Ting, Florian Keusch, and Lirui He. 2018. "The Impact of Question and Scale Characteristics on Scale Direction Effects.” Survey Practice 11 (2): 3126. https://doi.org/10.29115/sp-2018-0008. 